\title{
ESTUDO E DESENVOLVIMENTO DE FERTILIZANTE LÍQUIDO NITROGENADO
}

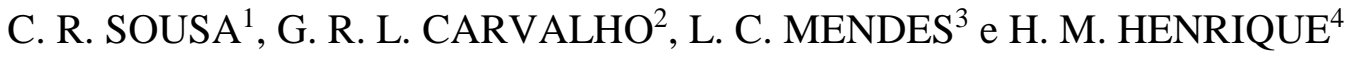 \\ 1, 2, 3 e 4 Universidade Federal de Uberlândia, Faculdade de Engenharia Química \\ E-mail para contato: ${ }^{1}$ camilaribeiro-camila@ hotmail.com, ${ }^{2}$ gui.ribeiro119@ gmail.com, \\ ${ }^{3}$ larissacarvalhoufu@gmail.com e $\mathrm{e}^{4}$ humberto@ufu.br
}

\begin{abstract}
RESUMO - O uso de fertilizantes líquidos no Brasil começou com a aplicação da chorume no século XIX e da vinhaça como adubo em 1950. Posteriormente, foram criados fertilizantes líquidos a base de amônia e também a produção de suspensões com diversas formulações de macronutrientes. Atualmente, a comercialização de fertilizantes líquidos foliares tem crescido bastante devido a questões de custo, ao aumento da produção de ácido fosfórico e ao desenvolvimento de equipamentos de aplicação segura, dentre outros. Este trabalho teve como objetivo estudar características físico-químicas de fertilizantes nitrogenados em diversas concentrações buscando obter produtos estáveis com alto teor de nitrogênio. Os critérios adotados para avaliar a qualidade dos fertilizantes foram tempo de agitação, $\mathrm{pH}$, densidade, sinérese, temperatura mínima de reação e temperatura de cristalização. As matérias primas utilizadas foram ureia e nitrato de amônio grau fertilizante. Entre os resultados encontrados, pode-se observar que a temperatura mínima de reação é menor quanto mais concentrada é o fertilizante e, percebeu-se também, que o pH não sofreu alteração de acordo com as concentrações.
\end{abstract}

\section{INTRODUÇÃO}

Fertilizantes líquidos são utilizados no mundo desde 1840 com a produção e comercialização de misturas fluido inorgânicos na Irlanda. Os primeiros registros de aplicação de aquamônia (reação de água e amônia anidra) são de 1843 na Escócia. No Brasil, no século XIX aplicava-se chorume no solo, porém, somente em 1960/1970 iniciou-se a comercialização de misturas sólidas e líquidas para aplicação foliar. Em 1979 iniciou-se a produção industrial de suspensões e, a partir de então, o estudo de diversas formulações para fertilizantes líquidos tornou-se mais comum (Intenational Fertilizer Industry Association, 1992).

Os fertilizantes líquidos, também chamados de fertilizantes fluidos, são classificados em solução verdadeira e suspensões. A solução verdadeira é geralmente translúcida e é possível ver através do líquido, isto é, ela é uma solução verdadeira, livre de sólidos. Já nas Suspensões não é possível ver através do líquido, existem pequenos sólidos/cristais em suspensão no líquido. As suspensões possuem a vantagem de serem mais concentradas uma vez que conseguem agregar mais nutrientes pois não têm a necessidade de solubilizá-los. Algumas formulações líquidas são aplicadas sobre as folhas e, por isto, os fertilizantes são chamados de foliares. Podem ainda ser aplicados via irrigação, cuja técnica é conhecida como fertirrigação. 
O uso de fertilizantes fluido-nitrogenados tem se tornado bastante popular nos últimos anos. (MCLAUGHLIN, 2008)

Fertilizantes líquidos apresentam vantagens em relação aos sólidos. Pode-se citar menor custo com mão-de-obra, movimentação e transporte do produto é feito através de bombas, a aplicação no solo é uniforme, menor segregação de nutrientes, é possível utilizar defensivos agrícolas durante a aplicação em campo, possui maior rendimento operacional durante a aplicação em campo, apresenta grande versatilidade nas formulações, permitindo o uso de micronutrientes, tem menor custo de produção e gera menor impacto ambiental no processo de fabricação (UNIDO, 1998; MCLAUGHLIN, 2008).

Pode-se citar como desvantagens a menor concentração de nutrientes em relação aos fertilizantes sólidos, necessidade de agitação do produto durante o transporte - no caso de suspensões - armazenamento e aplicação, maiores riscos de acidentes durante o processo de aplicação em campo, alta corrosividade, possibilidade de formação de precipitados e entupimento de bicos (UNIDO, 1998; MCLAUGHLIN, 2008).

A aplicação de fertilizantes fluidos no Brasil é comum em culturas de cana-de-açúcar. Esta possui grande exigência em nitrogênio e potássio. Tal fato explica o crescente uso de soluções nitrogenadas no país. As soluções nitrogenadas são conhecidas como soluções de URAN (Ureia e Nitrato de Amônia). Elas são utilizadas como adubo nitrogenado e também como solvente básico para formulações NPK. Para a produção de fertilizantes fluidos é preciso entender, portanto, o comportamento de soluções de fertilizantes fluidos nitrogenados e seu modo de preparação.

\section{OBJETIVO}

O objetivo deste trabalho foi estudar a produção de diversas concentrações de soluções de URAN e caracterizar os comportamentos físico-químicos. Tal estudo servirá de base para o levantamento de parâmetros de processo que possam ser utilizados em projeto conceitual de uma planta para produção de fertilizantes líquidos e foliares.

\section{METODOLOGIA}

\subsection{Materiais e Métodos}

As matérias primas utilizadas foram ureia $\left(\mathrm{CH}_{4} \mathrm{~N}_{2} \mathrm{O}\right.$ com $45 \%$ de $\left.\mathrm{N}\right)$ e nitrato de amônio $\left(\mathrm{NH}_{4} \mathrm{NO}_{3}\right.$ com $33 \%$ de $\left.\mathrm{N}\right)$ e água. Utilizou-se matérias primas comerciais, ou seja, grau fertilizante. Os cálculos de balanço foram realizados com o auxílio do diagrama de solubilidade das três espécies presentes, apresentado na Figura 1, fixada a temperatura de cristalização em $10^{\circ} \mathrm{C}$ (HIGNETT, 1985). Esta temperatura foi determinada como a mínima temperatura em que o fertilizante pode ser submetido sem que haja cristalização de parte dos sólidos dissolvidos. Foram obtidas três formulações nitrogenadas: 28-00-00, 30-00-00 e 32-00-00, utilizando como base de cálculo o preparo de $1000 \mathrm{~g}$ de solução.

As duas primeiras formulações foram obtidas em dois balanços diferentes, uma considerando a máxima concentração de ureia e a outra considerando a máxima concentração 
de nitrato de amônia nas formulações. A terceira formulação foi encontrada somente com uma única configuração da relação ureia/nitrato de amônia.

As soluções foram produzidas em um béquer de $2000 \mathrm{~mL}$ e agitador tipo hélices de acordo com os seguintes passos:

- Pesagem dos reagentes: água, nitrato de amônio, ureia;

- Aquecimento da água - aproximadamente $90^{\circ} \mathrm{C}$;

- Acionamento do agitador sob a água e adição dos demais reagentes.

Figura 1 - Diagrama ternário de solubilidade (ureia, nitrato de amônia e água)

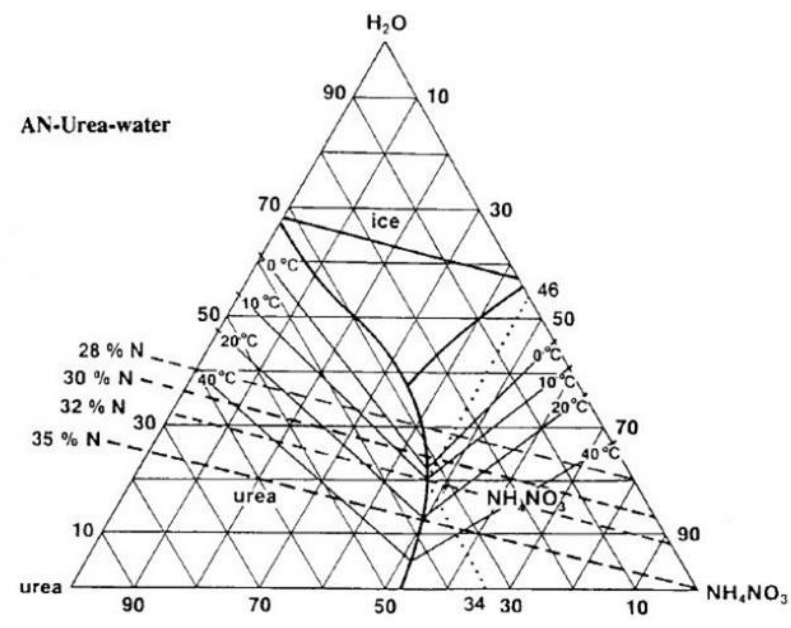

Fonte: http://migre.me/wkIEo (UreaKnowHow.com)

\subsection{Medidas e Caracterizações}

Durante o preparo das soluções realizou-se as seguintes medições:

Determinação do tempo médio de agitação: Foi utilizado um agitador mecânico IKA RW 20 Digital, compacto e versátil, possuindo visor em LED para indicação de velocidade. A velocidade de agitação empregada foi de $300 \mathrm{rpm}$. Um cronômetro digital foi utilizado para medir o tempo para a completa solubilização das soluções.

Temperaturas de reação: Com o uso de um termopar mediu-se a temperatura a todo tempo da reação. Registrou-se também as temperaturas inicial, final e mínima do processo de solubilização.

Determinação do pH: Após a completa solubilização da solução e final da reação, utilizou-se um medidor $\mathrm{pH}$ devidamente calibrado para a medida do $\mathrm{pH}$.

Determinação da densidade: Utilizou-se a técnica da picnometria. $\mathrm{O}$ picnômetro é um instrumento de vidro que possui baixo coeficiente de dilatação. Foi utilizada água destilada à temperatura ambiente e seus dados de propriedades físico-químicas tabelados na literatura. 
Temperatura de cristalização: Béqueres de $100 \mathrm{~mL}$ com cada solução foram mergulhados em um banho ultratermostatizado marca Marconi modelo MA 184 na função resfriamento. A temperatura de cristalização foi medida assim que os primeiros cristais foram formados na solução.

Massa de resíduo sólido: Cada solução foi filtrada utilizando papel de filtro com $18,5 \mathrm{~cm}$ de diâmetro e porosidade de 3 micrômetros e funil simples. Os resíduos retidos no papel de filtro foram secos na estufa com circulação e renovação de ar marca TECNAL modelo TE$394 / 1$ a $115^{\circ} \mathrm{C}$ durante $24 \mathrm{~h}$ e posteriormente pesados. A massa do resíduo foi calculada por diferença de massa antes e após a filtração e secagem.

\section{RESULTADOS}

Todos os testes foram feitos em quintuplicata para melhor tratamento estatístico. Os resultados estão apresentados na Tabela 1 abaixo.

Tabela 1 - Dados experimentais obtidos na preparação das soluções de URAN.

\begin{tabular}{ccccccccc}
\hline Formulação & TAG $(\min )$ & $\mathrm{T}_{0}\left({ }^{\circ} \mathrm{C}\right)$ & $\mathrm{T}_{\mathrm{M}}\left({ }^{\circ} \mathrm{C}\right)$ & $\mathrm{T}_{\mathrm{F}}\left({ }^{\circ} \mathrm{C}\right)$ & $\mathrm{pH}$ & $\rho\left(\mathrm{g} / \mathrm{cm}^{3}\right)$ & $\mathrm{T}_{\mathrm{c}}\left({ }^{\circ} \mathrm{C}\right)$ & $\mathrm{MRS}(\mathrm{g})$ \\
\hline $28-00-00(\mathrm{MU})$ & $23,6 \pm 7,7$ & $92,0 \pm 0,0$ & $16,9 \pm 2,0$ & $21,1 \pm 1,5$ & $6,4 \pm 0,1$ & $1,259 \pm 0,013$ & - & $4,107 \pm 1,540$ \\
$28-00-00$ (MN) & $33,0 \pm 3,4$ & $92,2 \pm 0,6$ & $13,5 \pm 1,0$ & $22,7 \pm 1,0$ & $6,3 \pm 0,0$ & $1,322 \pm 0,005$ & - & $4,978 \pm 1,624$ \\
$30-00-00(\mathrm{MU})$ & $30,0 \pm 0,0$ & $92,0 \pm 1,5$ & $12,1 \pm 1,3$ & $18,4 \pm 1,5$ & $6,3 \pm 0,1$ & $1,324 \pm 0,002$ & $-0,940$ & $8,763 \pm 1,548$ \\
$30-00-00(\mathrm{MN})$ & $40,0 \pm 0,0$ & $92,8 \pm 0,6$ & $9,8 \pm 1,3$ & $17,7 \pm 3,3$ & $6,3 \pm 0,1$ & $1,348 \pm 0,016$ & - & $7,584 \pm 1,482$ \\
$32-00-00$ & $58,0 \pm 5,6$ & $92,0 \pm 0,0$ & $8,3 \pm 0,2$ & $19,2 \pm 0,8$ & $6,3 \pm 0,0$ & $1,369 \pm 0,006$ & - & $7,265 \pm 1,019$ \\
\hline
\end{tabular}

TAG - Tempo de agitação (min);

$\mathrm{T}_{0}$ - Temperatura inicial de solubilização $\left({ }^{\circ} \mathrm{C}\right)$;

$\mathrm{T}_{\mathrm{M}}$ - Temperatura mínima atingida na solubilização $\left({ }^{\circ} \mathrm{C}\right)$;

$\mathrm{T}_{\mathrm{F}}-$ Temperatura final após a solubilização $\left({ }^{\circ} \mathrm{C}\right) ;$

$\mathrm{pH}$ - pH da solução após o preparo da mesma;

$\rho$ - Densidade da solução $\left(\mathrm{g} / \mathrm{cm}^{3}\right)$;

$\mathrm{T}_{\mathrm{C}}-$ Temperatura de cristalização da solução $\left({ }^{\circ} \mathrm{C}\right)$;

MRS - Massa de resíduo insolúvel obtida na preparação da solução (g);

MU - Solução preparada com a maior quantidade possível de ureia;

MN - Solução preparada com a maior quantidade possível de nitrato.

Todos os dados da Tabela 1 possuem intervalos de confiança de 95\%. As formulações que não apresentam temperatura de cristalização indicadas na tabela tiveram valores encontrados abaixo de $-1{ }^{\circ} \mathrm{C}$, não sendo possível obter valores negativos abaixo deste valor por limitação do equipamento. Os resíduos sólidos filtrados são resíduos insolúveis contidos nas matérias-primas uma vez que estas são de caráter comercial e não de pureza analítica. A etapa de filtração, por ter sido feita com funil simples, levou muito tempo para ser concluída.

Os dados apresentados na Tabela 1 revelam que existe variação no tempo de agitação de acordo com a concentração da solução preparada, de forma que as soluções com maiores concentrações necessitam de maior tempo sob agitação para a completa solubilização. É possível perceber também a considerável variação nas temperaturas mínimas alcançadas, de forma que quanto mais concentrada a solução, mais baixa a temperatura mínima. Isto prova que a solubilização em questão é endotérmica. Observa-se ainda que o pH e a densidade das 5 formulações não sofreram significantes variações. 
Abaixo, nas Figura 2, 3 e 4, podemos observar as soluções de URAN. Na Figura 2, comparamos as soluções de Máximo Nitrato (MN), na Figura 3, comparamos as soluções de Máxima Ureia (MU) e na Figura 4, apresentamos a solução de concentração 32-00-00.

Figura 2 - Soluções de URAN (MN)

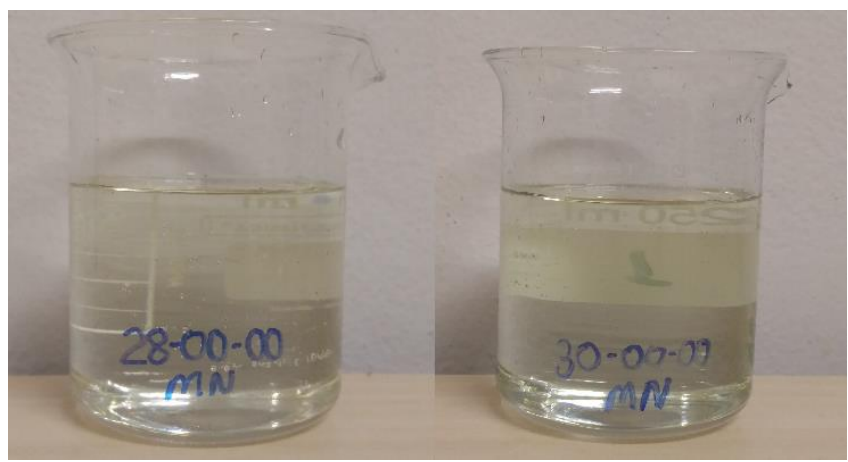

Figura 3 - Soluções de URAN (MU)

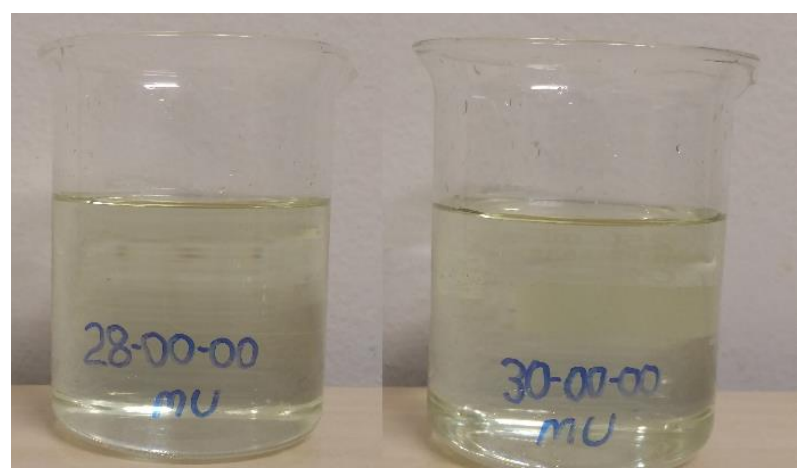

Figura 4 - Soluções de URAN (32-00-00)

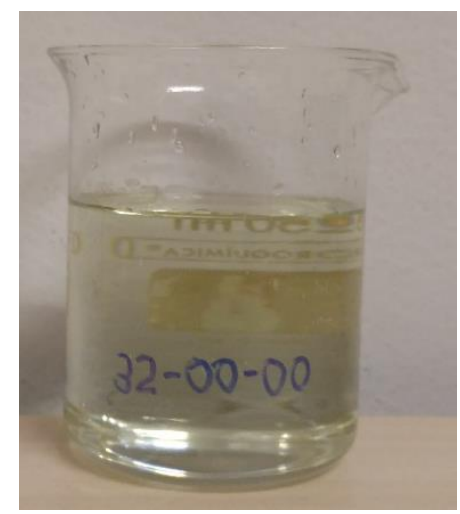

Na Figura 5 observa-se a diferença na coloração da menor e da maior concentração produzida. A solução 32-00-00 possui coloração mais esverdeada que as demais, e as soluções 28-00-00 são as menos esverdeadas. Observa-se, portanto, que quanto mais concentrada a solução do fertilizante nitrogenado, mais forte é sua coloração. 
Figura 5 - Comparativo das Soluções de URAN

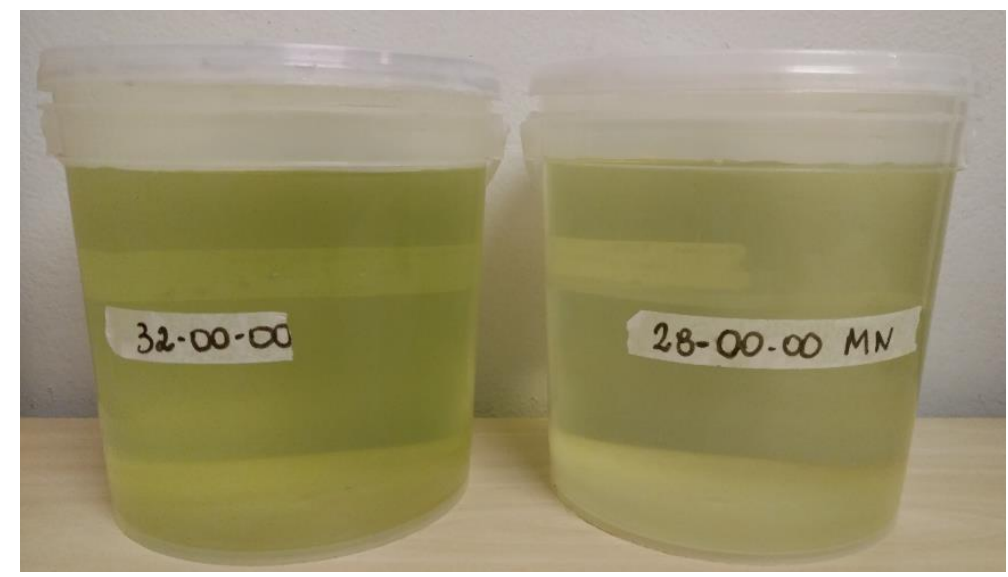

\section{CONCLUSÃO}

Assim como apresentado na literatura, soluções de URAN podem ser fabricadas utilizando ureia e nitrato de amônia como matérias primas. Tal solubilização é bastante endotérmica, necessitando o aquecimento da água até aproximadamente $90^{\circ} \mathrm{C}$, evitando-se, assim, o congelamento da solução. Também é possível observar que as temperaturas de cristalização destas formulações são muito baixas, favorecendo a não precipitação e formação de cristais durante a estocagem de produto em operações industriais.

Conclui-se ainda, que, no projeto de tanques de preparação de soluções URAN, o tempo de dissolução deve ser superior a 1 (uma) hora para a obtenção do produto final. Ainda, faz-se necessário o uso de filtros para a eliminação do resíduo insolúvel, podendo este ser um filtro inserido na tubulação, no caso de uma planta de produção, ou um filtro a vácuo, no caso de teste em bancada, de forma que esta etapa possa ser mais rápida.

\section{REFERÊNCIAS}

HIGNETT, T. P., NIJHOFF, M. Fertilizer Manual. Dordrecht. Boston - Lancaster. p. 129, 1985.

INTENATIONAL FERTILIZER INDUSTRY ASSOCIATION. Fertilizer Product Consumption Forecasts. Paris, France. A/92/116, 1992.

MCLAUGHLIN, M., THE UNIVERSITY OF ADELAIDE and CSIRO LAND AND WATER, Fluid Fertilizer: A South Australian Manual. Australia. p. 12, 2008.

UNITED NATIONS INDUSTRIAL DEVELOPMENT ORGANIZATION and INTERNATIONAL FERTILIZER DEVELOPMENT CENTER. Fertilizer Manual. Kluwer Academic Publishers. Netherlands. 1998. 